\title{
Operative outcomes in mitral valve surgery: Combined effect of surgeon and hospital volume in a population-based analysis
}

\author{
Arman Kilic, MD, ${ }^{\mathrm{a}}$ Ashish S. Shah, MD, ${ }^{\mathrm{a}}$ John V. Conte, MD, ${ }^{\mathrm{a}}$ William A. Baumgartner, MD, ${ }^{\mathrm{a}}$ and \\ David D. Yuh, MD ${ }^{\mathrm{b}}$
}

Objective: We evaluated the combined effect of hospital and surgeon volume on operative outcomes of mitral valve surgery in the United States.

\begin{abstract}
Methods: The Nationwide Inpatient Sample was used to identify adult patients undergoing isolated mitral valve surgery for mitral regurgitation from 2003 to 2008 . Hospitals and surgeons were separately stratified into equalsize tertiles according to annual overall mitral valve operative volumes. Multivariate logistic regression analysis was conducted, adjusting for multiple patient, hospital, and operative data, to determine the separate and combined effects of hospital and surgeon volume on operative outcomes.
\end{abstract}

\begin{abstract}
Results: A total of 50,152 eligible patients were identified during the study period. Although both hospital and surgeon volume correlated significantly with operative mortality in separate risk-adjusted analyses, only lower surgeon volume persisted as a significant risk factor in the combined risk-adjusted analysis. Moreover, although hospital volume only accounted for $10.7 \%$ of the surgeon volume effect on increased mortality for low-volume surgeons, surgeon volume accounted for $74.5 \%$ of the hospital volume effect on increased mortality in lowvolume hospitals. Surgeon, but not hospital, volume correlated with inpatient costs. Also, significant trends were seen with repair rates, with increasing surgeon volume demonstrating a relatively stronger correlation with the odds of repair $(P<.001)$ than hospital volume $(P=.01)$.

Conclusions: The effect of hospital volume on operative outcomes of mitral valve surgery was largely driven by the individual surgeon volumes within that hospital. Conversely, surgeon volume affected these outcomes independently of hospital volume. Identifying the processes by which higher volume surgeons attain better outcomes in mitral valve surgery would therefore be prudent. (J Thorac Cardiovasc Surg 2013;146:638-46)
\end{abstract}

Procedural volume is increasingly being recognized as an important contributor to operative outcomes. This has led the Leapfrog Group (Washington, DC) to adopt evidence-based hospital referral as a part of its safety standards to reduce nationwide mortality for several elective procedures, including cardiovascular procedures, such as coronary artery bypass grafting, percutaneous coronary interventions, aortic valve replacement, and abdominal aortic aneurysm repair. ${ }^{1}$ In several of the studies that have helped form the basis for these standards, either hospital volume or surgeon volume was examined separately, rather than being evaluated together in a combined analysis. ${ }^{2-5}$ This is a shortcoming, because it is unclear to what degree one affects the other. For example, it is conceivable

\footnotetext{
From the Division of Cardiac Surgery, ${ }^{\text {a }}$ Department of Surgery, Johns Hopkins Medical Institutions, Baltimore, Md; and Section of Cardiac Surgery, Department of Surgery, ${ }^{\mathrm{b}}$ Yale University School of Medicine, New Haven, Conn.

This study was supported by departmental funds from the Department of Surgery, Johns Hopkins Hospital, Baltimore, Md.

Disclosures: Authors have nothing to disclose with regard to commercial support. Received for publication March 12, 2012; revisions received June 8, 2012; accepted for publication July 26, 2012; available ahead of print Aug 22, 2012.

Address for reprints: David D. Yuh, MD, Section of Cardiac Surgery, Department of Surgery, Yale University School of Medicine, 330 Cedar St, Boardman 204, New Haven, CT 06510 (E-mail: david.yuh@yale.edu).

$0022-5223 / \$ 36.00$

Copyright (c) 2013 by The American Association for Thoracic Surgery http://dx.doi.org/10.1016/j.jtcvs.2012.07.070
}

that operative outcomes would be different in 2 hospitals with the same composite volume, with 1 having 100 surgeons each performing 5 procedures annually, and the other having 5 surgeons each performing 100 of the same procedures annually. Similarly, it is unclear whether hospital volume would modify the outcomes of a high- versus lowvolume surgeon to a different degree.

Similar to the other major cardiovascular procedures noted, the effect of either hospital or surgeon volume on operative outcomes in mitral valve surgery has been studied separately. The aim of the present study was to conduct a population-based analysis to evaluate the combined effect of hospital and surgeon volume on operative outcomes after mitral valve surgery in the United States.

\section{PATIENTS AND METHODS \\ Data Source}

We used the Agency for Healthcare Research and Quality Healthcare Cost and Utilization Project - Nationwide Inpatient Sample (NIS) data set, which is the largest all-payer inpatient database in the United States. Moreover, the NIS database contains patient-level hospital discharge data from 1050 hospitals in 44 states in the United States, approximating a $20 \%$ stratified sample of hospitals. ${ }^{6}$ After weighting, these data reflect about $95 \%$ of all hospital discharges in the United States. The database does not contain any identifiable patient information and is a publically available registry. The institutional review board therefore granted our study exempt status. 


\section{Abbreviations and Acronyms \\ ICD-9 = International Classification of Diseases, Ninth Revision \\ NIS $=$ Nationwide Inpatient Sample \\ STS $=$ Society of Thoracic Surgeons}

\section{Study Design}

The present study was a retrospective study limited to adult (age $\geq 18$ years) patients undergoing isolated mitral valve surgery for mitral regurgitation as identified in the NIS database from January 2003 to December 2008. The International Classification of Diseases, Ninth Revision (ICD-9) codes were used to identify eligible patients. Moreover, the ICD-9 procedure code 35.12 was used to identify mitral valve repairs and the ICD-9 procedure codes 35.23 and 35.24 were used to identify mitral valve replacement. Mitral regurgitation was identified by the diagnosis code 424.0. To maintain a homogenous study population and to limit confounding, those with mitral stenosis, rheumatic disease, infective endocarditis, or concomitant aortic valve disease were excluded from the analysis (ICD-9 diagnosis codes 093.21, 394.0, 394.1, 394.2, 396, 396.0, 396.3, 396.8, and 421.0).

Patients undergoing concomitant procedures were also excluded from the analysis. The ICD-9 codes for concomitant procedures included 35.11 (aortic valve repair), 35.21 or 35.22 (aortic valve replacement), $36.1 \mathrm{x}$ (coronary artery bypass grafting), 35.14 (tricuspid valve repair), and 35.27 or 35.28 (tricuspid valve replacement). Patients undergoing reoperative valve surgery were also excluded using the diagnosis code V43.3, which identifies patients with a previous heart valve prosthesis. For eligible patients, the primary outcome was operative mortality, defined as inhospital mortality occurring during the same admission as the mitral valve operation. Secondary outcomes included inpatient hospital costs and rates of mitral valve repair.

\section{Volume Categories}

The average annual hospital and surgeon volumes were calculated for all mitral valve operations. Hospitals and surgeons were separately classified into equal-size tertiles according to hospital and surgeon procedural volume, respectively. These tertiles were used to define low-, intermediate-, and high-volume hospitals or surgeons. Raw data plots were also generated to demonstrate operative outcomes at the individual surgeon or hospital level across the entire spectrum of volume.

\section{Variables}

The patient factors included in the present analysis were age, gender, race, and comorbidities. The clinical factors included type of mitral valve operation (ie, repair or replacement) and acuity (ie, elective vs urgent/ emergent). The system factors included payment status (ie, Medicare, Medicaid, self-pay or privately insured, or other form of payment), teaching status of hospital, geographic location of hospital, hospital volume, and surgeon volume. The year of operation was also included.

\section{Statistical Analysis}

Separate risk-adjusted multivariate logistic regression analyses were conducted to evaluate the separate effects of hospital or surgeon volume on operative mortality after mitral valve surgery. Because each of the listed patient, clinical, and system factors had less than $20 \%$ missing data, we included all of them in these risk-adjusted analyses. Patients with missing data entries were simply removed from the multivariate model. Logistic regression analysis adjusted for the same variables but including both hospital and surgeon volume in the model was also conducted to test the combined effect of these factors on operative mortality. Collinearity and significant interactions were thoroughly tested.

The proportion that surgeon volume contributed to the hospital volume effect was calculated by the following equation derived from previous published studies: $\left(\mathrm{OR}_{\mathrm{H}}-\mathrm{OR}_{\mathrm{HS}}\right) /\left(\mathrm{OR}_{\mathrm{H}}-1\right)$, where $\mathrm{OR}_{\mathrm{H}}$ is the odds ratio for hospital volume in risk-adjusted logistic regression analysis that included the hospital volume but excluded the surgeon volume, and $\mathrm{OR}_{\mathrm{HS}}$ is the odds ratio for hospital volume using the combined analysis that also included the surgeon volume. ${ }^{7}$ Similarly, the proportion that hospital volume contributed to the surgeon volume effect was calculated as follows: $\left(\mathrm{OR}_{\mathrm{S}}-\mathrm{OR}_{\mathrm{HS}}\right) /\left(\mathrm{OR}_{\mathrm{S}}-1\right)$, where $\mathrm{OR}_{\mathrm{S}}$ is the odds ratio obtained for surgeon volume in the risk-adjusted analysis that included the surgeon volume but excluded the hospital volume.

For cost analysis, we collected data on hospital costs rather than charges, because costs are a better estimation of resource use, and charges tend to reflect pricing decisions that take into account payer policies and other factors unrelated to resource usage. Costs were derived from hospital charges using the cost/charge ratios developed by the Agency for Healthcare Research and Quality using Centers for Medicare and Medicaid Services data. Similar to operative mortality, cost comparisons and comparisons of mitral valve repair rates were made between various surgeon and hospital strata.

In examining the data, we chose to exclude surgeons or hospitals with an average volume of less than 1 mitral valve operation annually, because these generally reflect coding errors within administrative databases such as the NIS, as demonstrated previously. ${ }^{7,8}$ All data included in the present study were weighted data, and survey statistics were therefore used for statistical comparisons. Moreover, we used the adjusted Wald test to compare continuous variables and a design-based Pearson's $\chi^{2}$ statistic for categorical data. All analyses were performed with STATA statistical software, version 11 (StataCorp LP, College Station, Tex).

\section{RESULTS}

\section{Study Population}

A total of 50,152 eligible patients were identified as undergoing isolated mitral valve surgery for mitral regurgitation during the study period (Table 1). Their mean age was $61.9 \pm 13.7$ years, with 16,851 patients $(33.6 \%)$ aged 70 years or older. The distribution of men $(52.7 \%$; $\mathrm{n}=26,430)$ and women $(47.3 \% ; \mathrm{n}=23,722)$ was roughly equal. Most operations were performed on an elective basis $(70.6 \% ; n=35,362)$ and were conducted at teaching hospitals $(67.0 \% ; \mathrm{n}=33,602)$. Also, most were mitral valve repairs $(50.7 \% ; n=25,427)$.

\section{Hospital and Surgeon Volume}

The mean annual hospital mitral valve volume was $89.4 \pm$ 75.1 cases/y (median, 61). When divided into equal-size tertiles, the thresholds for hospital volume were as follows: low (1-41 cases/y), intermediate (42-94.5 cases/y), and high ( $>94.5$ cases/y). For surgeon volume, the mean number of annual mitral valve operations was $22.9 \pm 30.5$ cases/y (median, 12 cases/y). The volume ranges for the equalsize tertiles were low (1-6.5 cases/y), intermediate (6.6-20.5 cases/y), and high (>20.5 cases/y).

\section{Operative Mortality}

The unadjusted operative mortality rate for the entire cohort was $3.4 \%$. In stratifying patients according to hospital 
TABLE 1. Study population characteristics

\begin{tabular}{|c|c|}
\hline Patient characteristic & Study population $(n=50,152$ \\
\hline Age (y) & $61.9 \pm 13.7$ \\
\hline Female gender & $23,722 / 50,152(47.3 \%)$ \\
\hline \multicolumn{2}{|l|}{ Race } \\
\hline Caucasian & $33,234 / 41,439(80.2 \%)$ \\
\hline African American & $3771 / 41,439(9.1 \%)$ \\
\hline Other & $4475 / 41,439(10.8 \%)$ \\
\hline \multicolumn{2}{|l|}{ Payment } \\
\hline Private insurance or self-pay & $23,425 / 50,054(46.8 \%)$ \\
\hline Medicare & $22,574 / 50,054(45.1 \%)$ \\
\hline Medicaid & $2603 / 50,054(5.2 \%)$ \\
\hline Other & $1452 / 50,054(2.9 \%)$ \\
\hline \multicolumn{2}{|l|}{ Comorbidity } \\
\hline Atrial fibrillation & $25,477 / 50,152(50.8 \%)$ \\
\hline Coronary artery disease & $11,585 / 50,152(23.1 \%)$ \\
\hline Myocardial infarction & $3109 / 50,152(6.2 \%)$ \\
\hline Congestive heart failure & $24,524 / 50,152(48.9 \%)$ \\
\hline Peripheral vascular disease & $1505 / 50,152(3.0 \%)$ \\
\hline Cerebrovascular disease & $1906 / 50,152(3.8 \%)$ \\
\hline COPD & $12,488 / 50,152(24.9 \%)$ \\
\hline Diabetes mellitus & $5166 / 50,152(10.3 \%)$ \\
\hline Chronic renal disease & $2658 / 50,152(5.3 \%)$ \\
\hline Liver disease & $201 / 50,152(0.4 \%)$ \\
\hline Charlson comorbidity index & $1.1 \pm 1.2$ \\
\hline \multicolumn{2}{|l|}{ Admission acuity } \\
\hline Elective & $35,362 / 50,088(70.6 \%)$ \\
\hline Urgent/emergent & $14,726 / 50,088(29.4 \%)$ \\
\hline Teaching hospital & $33,602 / 50,152(67.0 \%)$ \\
\hline \multicolumn{2}{|l|}{ Hospital region } \\
\hline Midwest & $8426 / 50,152(16.8 \%)$ \\
\hline Northeast & $14,494 / 50,152(28.9 \%)$ \\
\hline South & $21,465 / 50,152(42.8 \%)$ \\
\hline West & $5767 / 50,152(11.5 \%)$ \\
\hline \multicolumn{2}{|l|}{ Operation type } \\
\hline Mitral valve repair & $25,427 / 50,152(50.7 \%)$ \\
\hline Mitral valve replacement & $24,725 / 50,152(49.3 \%)$ \\
\hline
\end{tabular}

Frequency data presented as number (\%) and continuous data as mean \pm standard deviation. COPD, Chronic obstructive pulmonary disease.

volume, the unadjusted mortality for mitral valve repair ranged from $1.1 \%$ for high-volume centers to $1.8 \%$ for low-volume centers $(P=.20$; Figure 1$)$. For replacements, unadjusted mortality ranged from $4.6 \%$ to $5.8 \%$ in highand low-volume hospitals, respectively $(P=.35)$. With respect to surgeon volume, significant trends were observed, unlike with hospital volume. Moreover, the operative mortality ranged from $1.0 \%$ to $2.7 \%$ with repairs $(P=.008)$ and $3.6 \%$ to $7.4 \%$ with replacements $(P<.001)$ for highand low-volume surgeons, respectively (Figure 1). These trends were also evident when examining various combinations of surgeon and hospital volume and their effect on overall mortality rates (Figure 2).

When examined independently of surgeon volume, the hospital volume significantly affected risk-adjusted mortality, such that intermediate- and low-volume hospitals had greater mortality rates than high-volume centers (Table 2). Similarly, when examined independently of hospital volume, increasing surgeon volume was associated with significantly reduced risk-adjusted mortality. However, when both hospital and surgeon volume were included in the same risk-adjusted multivariate model, only low- and intermediate-volume surgeons were found to have a significantly increased risk of operative mortality. Low-volume surgeons had more than a twofold increase in risk-adjusted mortality compared with high-volume surgeons in the combined analysis (OR, 2.10; $P<.001$; Table 2$)$. Similarly, when the raw data were graphically plotted, a stronger decreasing trend in mortality was identified with increasing surgeon versus increasing hospital volume (Figure 3). This raw data plot also demonstrated that a cluster of lower volume surgeons and hospitals had attained acceptable outcomes, although, as a whole, lower volume surgeons or centers had greater mortality rates than higher volume providers.

\section{Relative Contributions of Hospital and Surgeon Volume to Operative Mortality}

Using the formulas described in the "Methods" section, surgeon volume accounted for $41.8 \%$ and $74.5 \%$ of the greater operative mortality risk seen in the intermediateand low-volume hospitals, respectively (Figure 4). Thus, surgeon volume was responsible for $10 \%$ of the $14 \%$ increase in risk-adjusted mortality seen in low-volume hospitals and for $13 \%$ of the $32 \%$ increase in intermediate-volume hospitals.

Conversely, hospital volume only accounted for $16.0 \%$ and $10.7 \%$ of the increased mortality seen in intermediateand low-volume surgeons, respectively (Figure 4). This translated into hospital volume only being responsible for $12 \%$ of the $110 \%$ increase in risk-adjusted mortality observed with low-volume surgeons and $7 \%$ of the $42 \%$ increase for intermediate-volume surgeons.

\section{Repair Rates}

Significant trends were found in the rates of mitral valve repair across hospital and surgeon volume strata. Use of mitral valve repair ranged from $43.8 \%$ in low-volume hospitals to $56.9 \%$ in high-volume hospitals $(P=.01)$. These trends in repair rates were even stronger with surgeon volume, ranging from $41.7 \%$ to $59.1 \%$ for low- and highvolume surgeons, respectively $(P<.001)$. After plotting the raw data, it was clear that increasing surgeon volume had a stronger correlation with increasing rates of repair, although hospital volume also had a significant association (Figure 5).

\section{Hospital Costs}

Hospital volume was not found to significantly affect inpatient costs within any of the surgeon volume strata (Figure 6). Conversely, surgeon volume had a significant effect on inpatient costs across all hospital volume strata, 


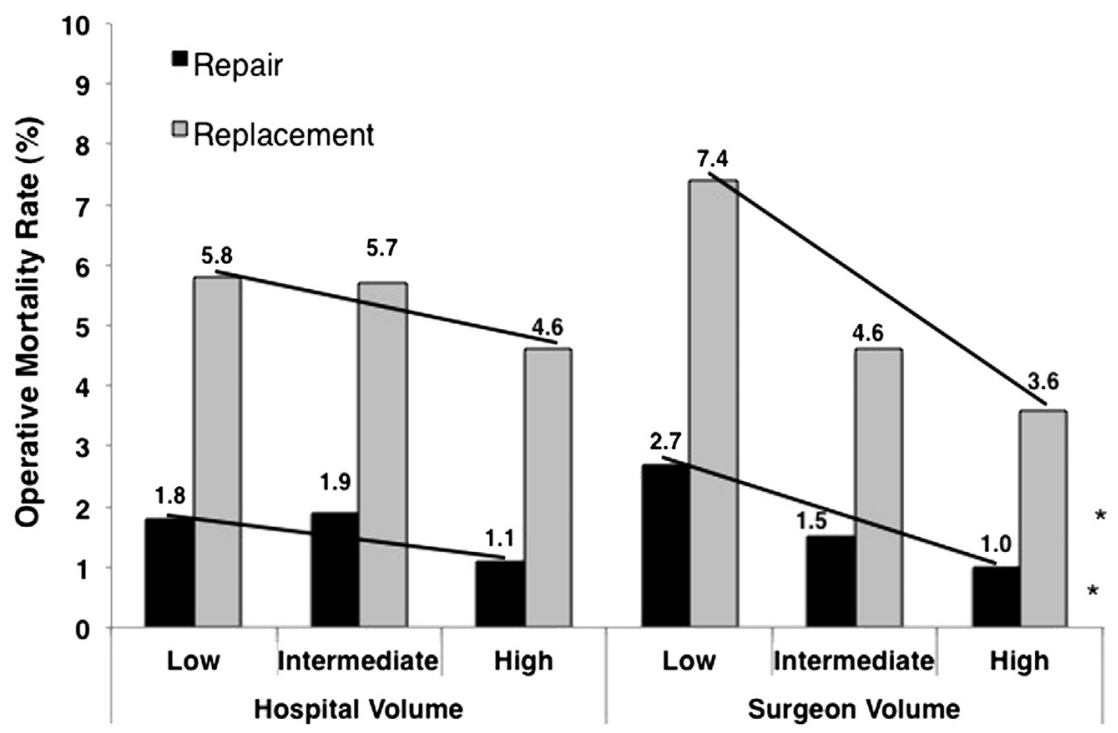

FIGURE 1. Trends in operative mortality, stratified by surgeon and hospital volume and mitral valve repair versus replacement. *P value $<.05$ for trend in decreasing mortality with increasing volume.

with low-volume surgeons consistently having the greatest associated hospital costs (each, $P<.05$ ).

\section{DISCUSSION}

The surgical management of mitral valve disease has evolved significantly during the past decade. Moreover, mitral valve repair has become the preferred option over replacement because of the improved survival and avoidance of anticoagulation. ${ }^{9-12}$ Furthermore, the overall number of mitral valve operations on a national level is thought to be increasing owing to the aging population in conjunction with expected increases in the prevalence of cardiovascular disease. ${ }^{13}$ With these ongoing nationwide changes, an analysis of factors that contribute to outcomes in a modern cohort of patients is prudent.

\section{Use of NIS Registry}

Recently, attention has shifted to nonpatient factors that might influence operative mortality in high-risk surgery, such as hospital teaching status, hospital procedural volume, surgeon age, surgeon specialty, and surgeon procedural volume. $^{2-5,7,8,14-19}$ In the present study, we used the NIS database to examine the effect of hospital and surgeon volume on operative mortality in mitral valve surgery. We chose to use this registry for several reasons. Foremost, the NIS is the largest all-payer database in the United States and therefore can provide a "real-world snapshot" of inpatient outcomes that other multicenter registries are unable to provide. Furthermore, because the NIS is a mandated registry, the effect of reporting bias is reduced. The effect of reporting biases in clinical registries such as the Society of Thoracic Surgeons (STS) database is unknown. A recent study of lung cancer resection, for instance, demonstrated that the STS national database represented only a small percentage of lung resections performed nationally (as determined by the NIS database) and tended to report significantly lower mortality rates than the national results. ${ }^{20}$ This questions the broad generalizability of clinical registries that have select reporting. Finally, we believe our use of the NIS database was supported by the multitude of high-quality and high-impact volume-outcomes analyses that have been performed using this registry. $5,7,21,22$

\section{Study Findings}

The principal finding of our analysis was that surgeon volume affects operative mortality, irrespective of hospital volume, and the effect of hospital volume on operative mortality is dependent on the individual surgeon volumes within that hospital. We also found parallel trends with inpatient costs of care, with low-volume surgeons having

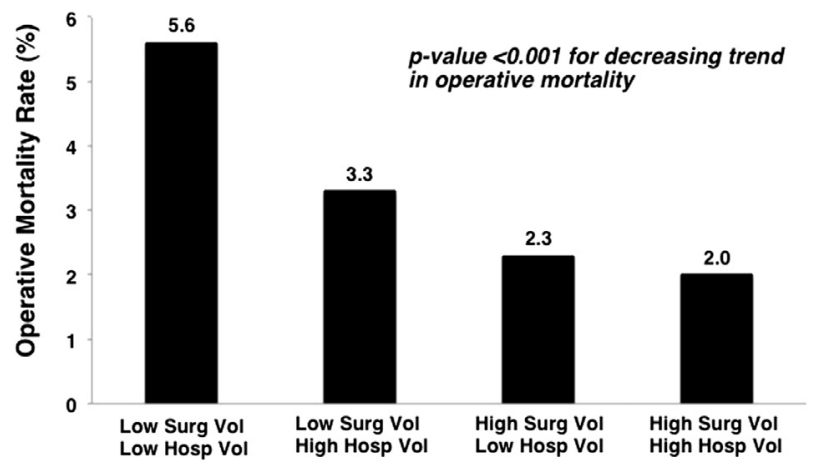

FIGURE 2. Operative mortality for various combinations of surgeon and hospital volume. 
TABLE 2. Univariate and multivariate logistic regression analysis evaluating effect of hospital and/or surgeon volume on operative mortality

\begin{tabular}{|c|c|c|c|c|}
\hline \multirow[b]{2}{*}{ Covariate } & \multicolumn{2}{|c|}{ Univariate analysis } & \multicolumn{2}{|c|}{ Multivariate analysis } \\
\hline & OR $(95 \%$ CI $)$ & $P$ value & OR $(95 \%$ CI $)$ & $P$ value \\
\hline \multicolumn{5}{|c|}{ Hospital volume (no surgeon volume) } \\
\hline High & Reference & & Reference & \\
\hline Intermediate & $1.45(1.01-2.07)$ & .04 & $1.55(1.05-2.29)$ & .03 \\
\hline Low & $1.57(1.14-2.16)$ & .006 & $1.55(1.02-2.35)$ & .04 \\
\hline \multicolumn{5}{|c|}{ Surgeon volume (no hospital volume) } \\
\hline High & Reference & & Reference & \\
\hline Intermediate & $1.48(1.05-2.07)$ & .02 & $1.50(1.07-2.11)$ & .02 \\
\hline Low & $2.73(1.95-3.82)$ & $<.001$ & $2.22(1.53-3.23)$ & $<.001$ \\
\hline \multicolumn{5}{|c|}{ Hospital volume (with surgeon volume) } \\
\hline High & Reference & & Reference & \\
\hline Intermediate & $1.45(1.01-2.07)$ & .04 & $1.32(0.91-1.91)$ & .15 \\
\hline Low & $1.57(1.14-2.16)$ & .006 & $1.14(0.75-1.75)$ & .54 \\
\hline \multicolumn{5}{|c|}{ Surgeon volume (with hospital volume) } \\
\hline High & Reference & & Reference & \\
\hline Intermediate & $1.48(1.05-2.07)$ & .02 & $1.42(1.00-2.02)$ & .05 \\
\hline Low & $2.73(1.95-3.82)$ & $<.001$ & $2.10(1.41-3.13)$ & $<.001$ \\
\hline Age (increasing) & $1.06(1.05-1.07)$ & $<.001$ & $1.04(1.03-1.06)$ & $<.001$ \\
\hline Female gender & $1.55(1.25-1.92)$ & $<.001$ & $1.18(0.92-1.51)$ & .20 \\
\hline \multicolumn{5}{|l|}{ Race } \\
\hline Caucasian & Reference & & Reference & \\
\hline African American & $1.20(0.82-1.75)$ & .35 & $0.88(0.56-1.39)$ & .58 \\
\hline Other & $1.20(0.80-1.78)$ & .38 & $1.16(0.74-1.82)$ & .51 \\
\hline \multicolumn{5}{|l|}{ Payment status } \\
\hline Private or self-pay & Reference & & Reference & \\
\hline Medicare & $5.01(3.72-6.74)$ & $<.001$ & $1.92(1.24-2.95)$ & .003 \\
\hline Medicaid & $3.18(1.83-5.51)$ & $<.001$ & $2.19(1.30-3.71)$ & .004 \\
\hline Other & $1.31(0.45-3.87)$ & .62 & $0.76(0.21-2.74)$ & .68 \\
\hline \multicolumn{5}{|l|}{ Comorbidity } \\
\hline Atrial fibrillation & $0.83(0.64-1.07)$ & .15 & $0.54(0.40-0.72)$ & $<.001$ \\
\hline Coronary artery disease & $1.73(1.34-2.23)$ & $<.001$ & $0.74(0.49-1.12)$ & .16 \\
\hline Myocardial infarction & $3.35(2.34-4.78)$ & $<.001$ & $2.41(1.40-4.14)$ & .002 \\
\hline Congestive heart failure & $2.98(2.26-3.93)$ & $<.001$ & $1.46(1.07-1.99)$ & .02 \\
\hline Peripheral vascular disease & $2.84(1.84-4.37)$ & $<.001$ & $1.99(1.21-3.25)$ & .007 \\
\hline Cerebrovascular disease & $2.03(1.29-3.20)$ & .002 & $1.42(0.76-2.65)$ & .27 \\
\hline COPD & $1.18(0.91-1.54)$ & .20 & $0.93(0.70-1.24)$ & .63 \\
\hline Diabetes mellitus & $0.89(0.61-1.31)$ & .56 & $0.56(0.35-0.92)$ & .02 \\
\hline Chronic renal disease & $2.37(2.03-2.75)$ & $<.001$ & $2.05(1.73-2.43)$ & $<.001$ \\
\hline Liver disease & $6.34(2.83-14.2)$ & $<.001$ & $4.84(2.09-11.2)$ & $<.001$ \\
\hline Urgent or emergent surgery & $3.41(2.68-4.34)$ & $<.001$ & $2.01(1.53-2.64)$ & $<.001$ \\
\hline Nonteaching hospital & $1.15(0.88-1.50)$ & .32 & $0.90(0.63-1.27)$ & .53 \\
\hline \multicolumn{5}{|l|}{ Hospital region } \\
\hline Midwest & Reference & & Reference & \\
\hline Northeast & $1.47(0.91-2.37)$ & .12 & $1.39(0.75-2.59)$ & .30 \\
\hline South & $1.75(1.11-2.75)$ & .02 & $1.35(0.74-2.45)$ & .32 \\
\hline West & $1.12(0.67-1.90)$ & .66 & $0.96(0.49-1.89)$ & .90 \\
\hline Mitral valve replacement & $3.55(2.72-4.65)$ & $<.001$ & $2.12(1.56-2.89)$ & $<.001$ \\
\hline
\end{tabular}

$O R$, Odds ratio; $C I$, confidence interval; $C O P D$, chronic obstructive pulmonary disease.

greater costs across all hospital volume strata. Finally, we found significant differences in the rate of mitral valve repair use across surgeon volume and hospital volume strata. These differences in repair rates were more pronounced across the spectrum of surgeon volume than hospital volume, although the latter also demonstrated a significant correlation. Although the overall repair rates for the entire study cohort were lower than those reported by studies using the STS database, we believe these differences likely reflect that STS-participating surgeons and hospitals have greater rates of repair than nonparticipating providers, which would tend to overestimate the real-world repair 


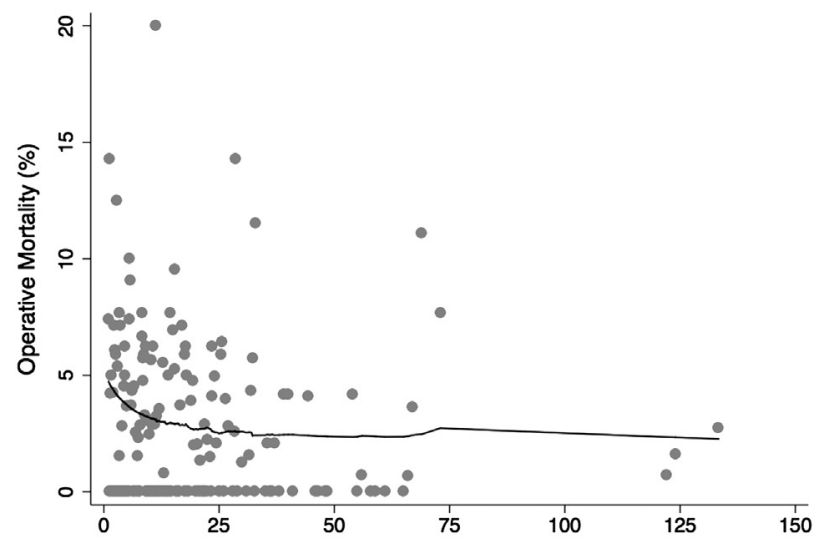

A

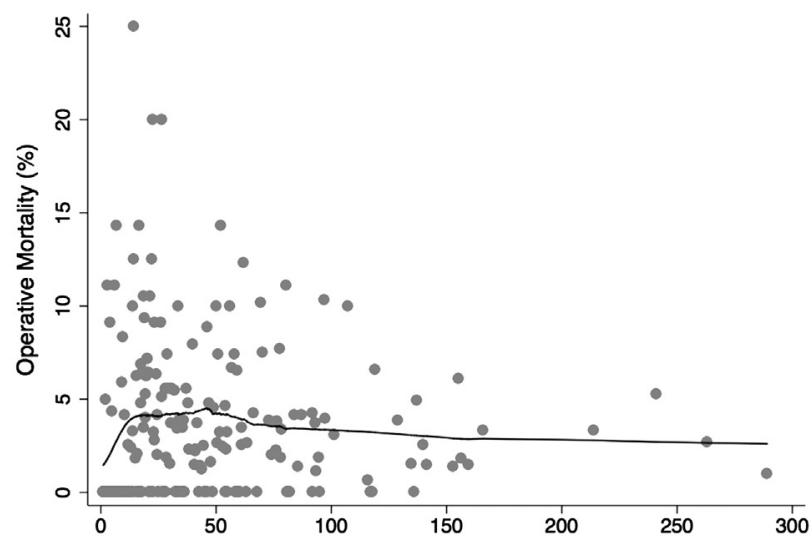

B

Annual Hospital Volume

FIGURE 3. Operative mortality rates examined at (A) individual surgeon or (B) center level.

rate, which is better judged using NIS data. In addition, these STS studies had different patient populations than ours, with 1 in particular excluding emergency operations,

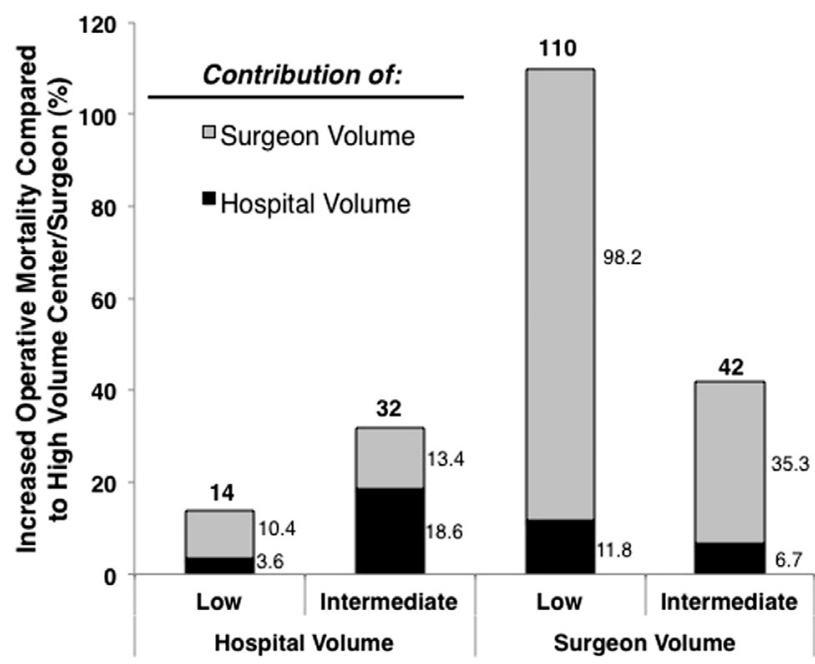

FIGURE 4. Relative contributions of hospital and surgeon volume to increased operative mortality risk for lower volume centers and surgeons.
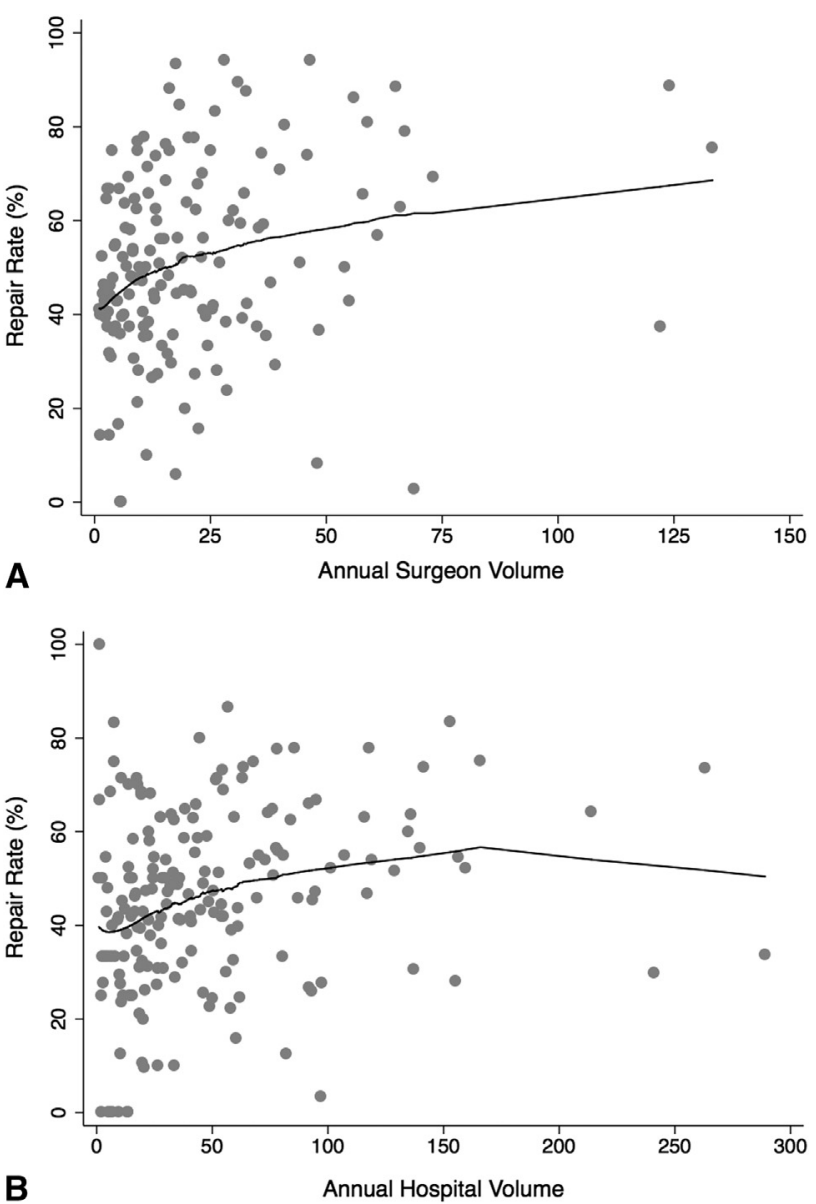

FIGURE 5. Mitral valve repair rates examined at (A) individual surgeon or (B) center level.

which would be expected to increase the proportion of repairs in their study cohort. ${ }^{9}$

\section{Implications}

There are several potential implications of our data. One recommendation based on these data might be that mitral valve operations should be preferentially performed by surgeons with high mitral volumes. Although national operative mortality rates might be reduced with such a policy, it is important to note that many low-volume surgeons attain excellent outcomes. As demonstrated in Figure 3, a significant cluster of surgeons with low annual volumes also had low operative mortality. Therefore, our data are not meant to impugn all low-volume surgeons, because some certainly have outcomes comparable to those of higher volume surgeons. There might also be a positive effect for a lower volume in that experienced surgeons with smaller practices might have more time to care for each patient, which could optimize results. Additionally, in clinical practice, lowvolume surgeons who were earlier in their career tend to have a greater percentage of emergency cases, many of 


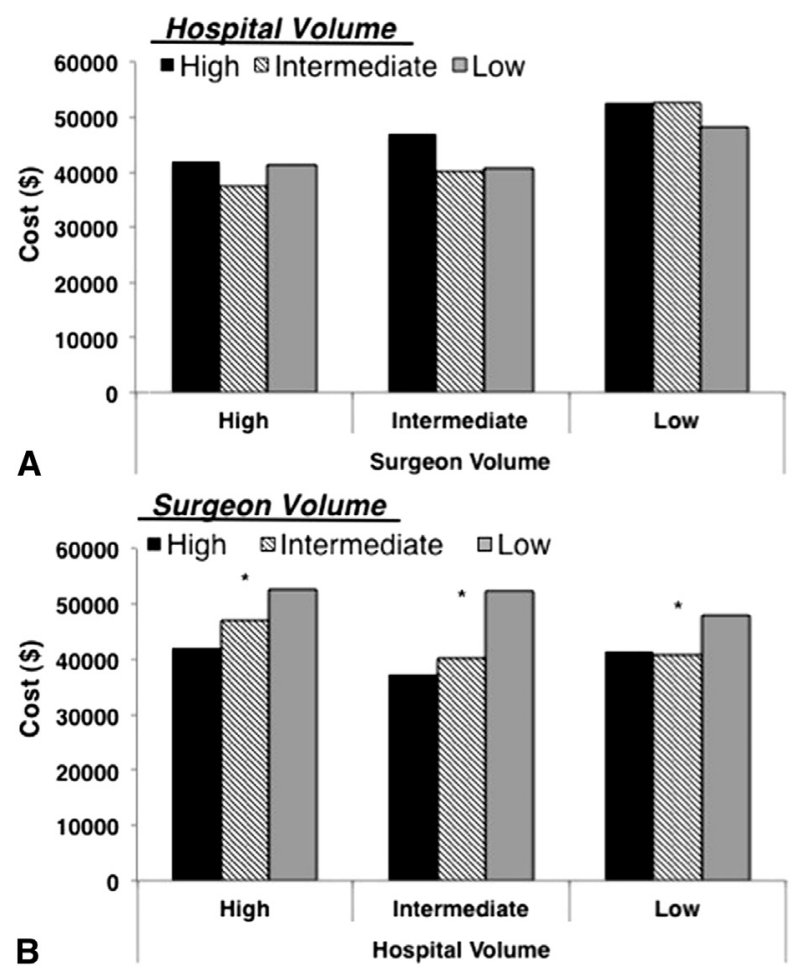

FIGURE 6. Trends in inpatient hospital costs stratified by various (A) hospital and (B) surgeon volume combinations. ${ }^{*} P<.05$.

which are performed on the weekend. This could have contributed to these varying outcomes, although we did perform a risk adjustment for elective versus emergency operations in our multivariate model.

Related to this concept is that our analysis was not designed to identify causal relationships, merely associative ones. Therefore, we cannot state for certain that volume drives outcomes. It might be that surgeons who have excellent outcomes do so from an early stage in their career. As their reputation and referral base grows, these wellperforming surgeons likely have significant increases in their annual operative volumes. Therefore, it might be that outcomes drive volume to a certain degree.

Despite this, our data have shown that at a national level, higher surgeon volume correlates with greater rates of repair and improved outcomes. Furthermore, this relationship exists largely irrespective of hospital volume. It might, therefore, be prudent to identify the specific processes by which higher volume surgeons attain better results and attempt to translate these processes to poorly performing low-volume surgeons. It could be that surgical qualities such as clinical judgment and technical expertise largely account for these volume-outcomes relationships, in which case, experience will be the answer to improving outcomes. However, other, more specific, processes of care could also be important. For instance, reviewing a surgeon's adherence to clinical guidelines or proven quality metrics might identify divergent practices that can be addressed for improvement in outcomes. One such divergent practice could be repair rates, which we identified as being significantly different between surgeon volume cohorts. Education and adoption of repair enabling techniques and technology will undoubtedly be important measures to improve these repair rates among lower volume surgeons.

Our finding of surgeon volume affecting outcomes to a greater degree than hospital volume does have intuitive validity. Moreover, mitral valve operations are technically challenging; therefore, it would be expected that a surgeon's previous operative experience would play an important role in outcomes. As supported by previous data, there is likely a spectrum of procedures for which hospital and surgeon volume contribute different proportions to surgical mortality risk according to the nature of the procedure and its associated postoperative care. ${ }^{7}$ For instance, esophagectomy, although technically demanding, also entail a large component of postoperative care. In such cases, hospital volume might affect outcomes to an equal or greater extent than surgeon volume. On the other end of the spectrum, for patients undergoing carotid endarterectomy, who are discharged the following day, technical expertise would seem to play a larger role than the postoperative care component. In such cases, surgeon volume would be expected to influence operative outcomes to a greater degree than hospital volume.

\section{Previous Studies of Surgeon or Hospital Volume in Mitral Valve Surgery}

Only a few reports have examined the volume-outcomes relationship in mitral valve surgery. One such study used the STS database and analyzed more than 13,000 patients undergoing elective surgery for mitral regurgitation between 2000 and 2003. ${ }^{18}$ Hospitals with higher procedural volumes were found to have reduced risk-adjusted operative mortality, increased rates of mitral valve repair, and greater rates of bioprosthetic use for older patients. ${ }^{18}$ However, that analysis did not incorporate individual surgeon volume. Another study also used the STS database in a more modern cohort (2005-2007) and found that of the 28,507 patients undergoing isolated mitral valve surgery, higher surgeon volume correlated with a greater probability of repair. ${ }^{19}$ In that analysis, hospital volume was not analyzed concurrently with surgeon volume.

We believe our findings add to the knowledge of the volume-outcomes relationship in mitral valve surgery by demonstrating that surgeon volume affects outcomes across all hospital strata but that the effect of hospital volume is significantly driven by the individual surgeon volumes within that hospital. By incorporating both surgeon and hospital volume into our analyses, we believe our study is unique to the mitral valve data. Moreover, when analyzing either hospital or surgeon volume, but not both, the 
importance of these variables can be skewed by not taking the other into account.

\section{Inpatient Costs of Care}

With regard to the hospital costs associated with the mitral valve procedure, we found trends similar to those observed with mortality. This also has intuitive validity, because patients who do not survive to discharge tend to have operative complications that can result in more complex postoperative management, longer intensive care unit stays, and repeat procedures that exponentially increase the cost of care. Therefore, it is not unexpected that surgeon volume, which correlated strongly with operative mortality, also correlated strongly with inpatient costs.

\section{Study Limitations}

Our study had several limitations. Some of these were related to the NIS database. For instance, we were unable to control for the variables included in the data set. One such variable that would be important to include but was not available was the specific etiology of mitral valve insufficiency. Although we had comorbidity data available (eg, atrial fibrillation, coronary artery disease), we could not state for certain that these comorbidities were the underlying causes of the mitral valve regurgitation. Although it is unlikely that surgeon and hospital volume would be affected disproportionately by the unmeasured variables in our risk adjustment, a possibility always exists that the inclusion of additional covariates would have altered the results. Validation of our data in a clinically driven registry is therefore prudent.

Moreover, errors in entry are inherent to any multicenter database. We tried to minimize this effect by excluding cases in which the average annual hospital or surgeon volume was less than 1 case annually. Missing data were also inherent in these multi-institutional data sets, although the variables included in our analyses had less than $20 \%$ missing data. Because the NIS is limited to inpatient outcomes, we could not conduct a longitudinal analysis to determine the effect of volume on longer term survival.

Another major limitation was that our study was not designed to delineate between associative versus causal relationships. Moreover, it is unclear from our analysis whether surgeon volume was related to lower operative mortality because of a "practice makes perfect" phenomenon or whether technically superior surgeons receive more referrals because of their better outcomes. Thus, it is unknown whether surgeon volume drives the lower operative mortality, or lower operative mortality drives the higher surgeon volume. We were also unable to include surgeon experience in years or the surgeons' overall volume with cardiac surgical procedures, although these could certainly affect outcomes. Many surgeons also operate in multiple hospitals and this could have confounded the results.

\section{CONCLUSIONS}

In the present large-cohort analysis of more than $50,000 \mathrm{pa}-$ tients, we examined the separate and combined effects of hospital and surgeon volume on operative mortality, inpatient costs, and rates of repair in mitral valve surgery. We found that lower surgeon volume significantly increased the operative mortality risk and did so independently of hospital volume. Conversely, the effect of hospital volume on surgical mortality was largely explained by the surgeon volume, which contributed to its effect substantially. Similar trends were observed with inpatient costs and rates of repair. These data collectively suggest that identifying the processes by which higher volume surgeons attain better outcomes in mitral valve surgery is prudent for improving nationwide outcomes.

\section{References}

1. The Leapfrog Group Web site. Available from: http://www.leapfroggroup.org Accessed March 9, 2012

2. Moscucci M, Share D, Smith D, O’Donnell MJ, Riba A, McNamara R, et al. Relationship between operator volume and adverse outcomes in contemporary percutaneous coronary intervention practice: an analysis of a quality-controlled multicenter percutaneous coronary intervention clinical database. JAm Coll Cardiol. 2005;46:625-32.

3. Begg CB, Cramer LD, Hoskins WJ, Brennan MF. Impact of hospital volume on operative mortality for major cancer surgery. JAMA. 1998;280:1747-51.

4. Manheim LM, Sohn MW, Feinglass J, Ujiki M, Parker MA, Pearce WH. Hospital vascular surgery volume and procedure mortality rates in California, 1982-1994. J Vasc Surg. 1998;28:45-56.

5. Birkmeyer JD, Siewers AE, Finlayson EV, Stukel TA, Lucas FL, Batista I, et al. Hospital volume and surgical mortality in the United States. N Engl J Med. 2002 346:1128-37.

6. Healthcare Cost and Utilization Project. Overview of the Nationwide Inpatient Sample. Available from: http://www.hcup-us.ahrq.gov/nisoverview. jsp. Accessed March 9, 2012.

7. Birkmeyer JD, Stukel TA, Siewers AE, Goodney PP, Wennberg DE, Lucas FL. Surgeon volume and operative mortality in the United States. $N$ Engl J Med. 2003;349:2117-27

8. Mayer EK, Bottle A, Darzl AW, Athanasiou T, Vale JA. The volume-mortality relation for radical cystectomy in England: retrospective analysis of hospital episode statistics. BMJ. 2010;340:c1128.

9. Gammie JS, Sheng S, Griffith BP, Peterson ED, Rankin JS, O'Brien SM, et al. Trends in mitral valve surgery in the United States: results from the Society of Thoracic Surgeons adult cardiac database. Ann Thorac Surg 2009;87:1431-9

10. Moss RR, Humphries KH, Gao M, Thompson CR, Abel JG, Fradet G, et al. Outcome of mitral valve repair or replacement: a comparison by propensity score analysis. Circulation. 2003;108:II90-7.

11. Daneshmand MA, Milano CA, Rankin JS, Honeycutt EF, Swaminathan M, Shaw LK, et al. Mitral valve repair for degenerative disease: a 20-year experience. Ann Thorac Surg. 2009;88:1828-37.

12. Daneshmand MA, Milano CA, Rankin JS, Honeycutt EF, Shaw LK, Davis RD et al. Influence of patient age on procedural selection in mitral valve surgery Ann Thorac Surg. 2010;90:1479-85.

13. Ad N, Barnett SD, Speir AM, Massimiano PS. Institutional and national trends in isolated mitral valve surgery over the past decade. Curr Opin Cardiol. 2008;23: 99-104.

14. Hannan EL, Radzyner M, Rubin D, Dougherty J, Brennan MF. The influence of hospital and surgeon volume on in-hospital mortality for colectomy, gastrectomy, and lung lobectomy in patients with cancer. Surgery. 2002;131:6-15.

15. Meguid RA, Brooke BS, Perler BA, Freischlag JA. Impact of hospital teaching status on survival from ruptured abdominal aortic aneurysm repair. $J$ Vasc Surg. 2009;50:243-50.

16. Waljee JF, Greenfield LJ, Dimick JB, Birkmeyer JD. Surgeon age and operative mortality in the United States. Ann Surg. 2006;244:353-62.

17. Goodney PP, Lucas FL, Stukel TA, Birkmeyer JD. Surgeon specialty and operative mortality with lung resection. Ann Surg. 2005;241:179-84. 
18. Gammie JS, O'Brien SM, Griffith BP, Ferguson TB, Peterson ED. Influence of hospital procedural volume on care process and mortality for patients undergoing elective surgery for mitral regurgitation. Circulation. 2007;115:881-7.

19. Bolling SF, Li S, O'Brien SM, Brennan JM, Prager RL, Gammie JS. Predictors of mitral valve repair: clinical and surgeon factors. Ann Thorac Surg. 2010;90:1904-11.

20. Lapar DJ, Bhamidipati CM, Lau CL, Jones DR, Kozower BD. The Society of Thoracic Surgeons General Thoracic Surgery database: establishing generaliz- ability to national lung cancer resection outcomes. Ann Thorac Surg. 2012;94: 216-21.

21. Nallamothu BK, Gurm HS, Ting HH, Goodney PP, Rogers MA, Curtis JP, et al. Operator experience and carotid stenting outcomes in Medicare beneficiaries. JAMA. 2011;306:1338-43.

22. Finks JF, Osborne NH, Birkmeyer JD. Trends in hospital volume and operative mortality for high-risk surgery. N Engl J Med. 2011;364:2128-37. 